\section{Top US bad breath formula arrives in UK}

\section{The Breath Co.}

DENTIST RECOMMENDED

FRESH BREATH

TOOTHPASTE

AntiCavity/AntiTartar

Formula

D. fancd later

75 mie

The top-selling specialist breath care formula in the US is now available in the UK.

The Breath Company's oral healthcare system is clinically proven to be effective at controlling the sulphur-producing bacteria that can cause bad breath. Each of the products in the range targets the bacteria living and multiplying on the tongue and throat's surface that causes halitosis, rather than masking the odour with powerful flavours.

Designed to work instantly and to keep working for over 12 hours to keep breath smelling fresh, using its specialist oxygen and fluoride technology, each of the Breath Company products works on all types of bad breath and xerostomia and contains no harsh ingredients such as alcohol, detergents, artificial flavours, colours, animal products or gluten.

The range includes Breath Company Fresh Breath Fluoride toothpaste in mild mint; Oral Rinse in Icy Mint or Mild Mint; and Mouth Wetting Dry Mouth Lozenges in Mandarin Mint.

\section{Making toothbrushing fun}

Award-winning British design company j-me offer a range of quirky and colourful toothbrush and toothpaste holders aimed at children.

These include toothpaste holders shaped like a lobster and a plane; toothbrush holders shaped like animals including lizards that 'crawl' up the bathroom wall; a toothbrush holder shaped like a boat; and a bathroom tidy shaped like a smiling whale. The popular products are designed to add an element of fun to the toothbrushing routine for children.

For dental practices interested in buying the products at trade, email kirsty@j-me.com.

A selection of $j$-me products are also available from the BDA Museum shop, call 0207463 4549 or email museum@bda.org.

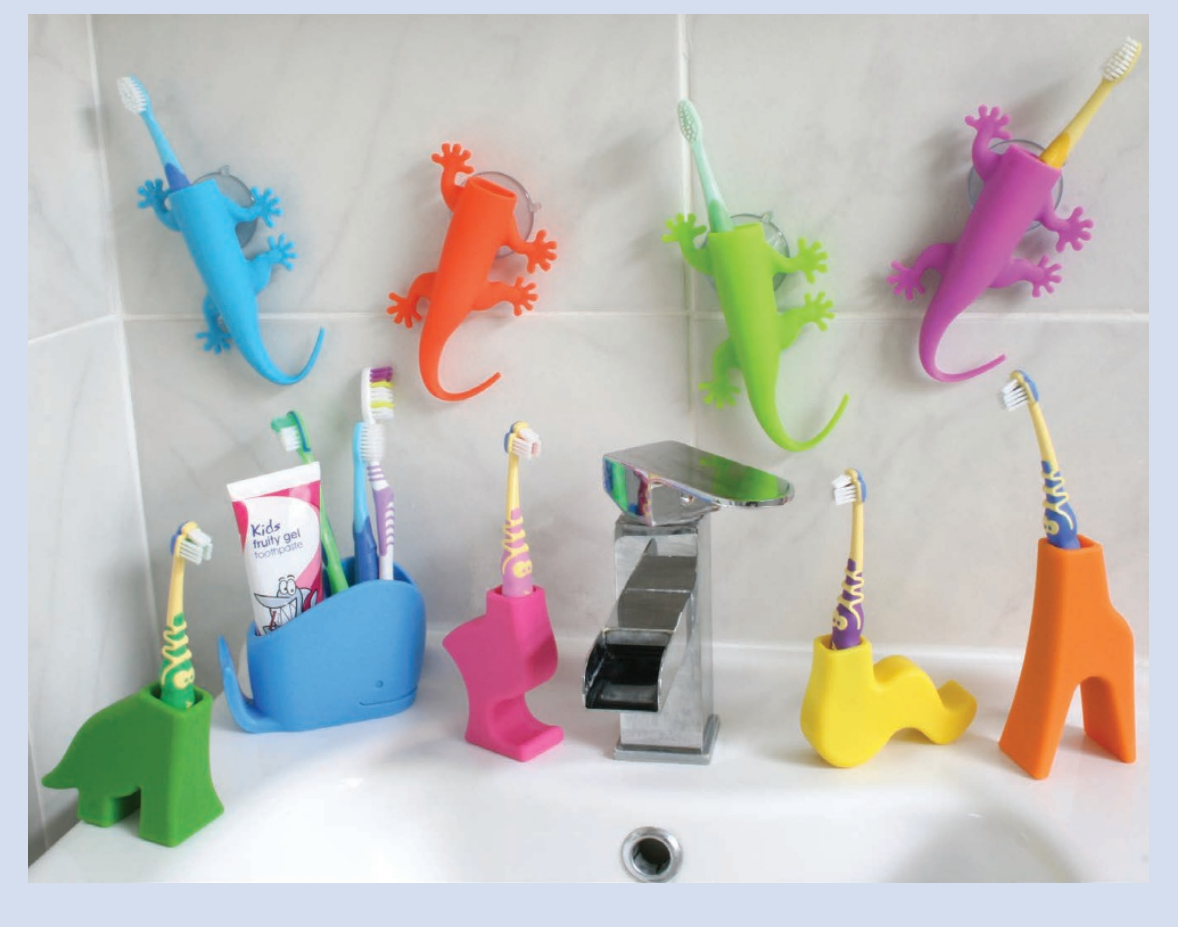

\title{
Families encouraged to brush this summer
}

For a second year, Denplan is running 'The Big Summer Brush-Up' to encourage families to make the most of the summer holidays to visit the dentist and spend time practising brushing techniques with their children.

A survey of parents of children aged 1-11 from Denplan, has revealed that almost a third (30\%) of parents think that it is acceptable for a child to have experienced tooth decay before they have reached their teenage years. According to the survey many parents try a multitude of methods to help their children manage their oral health effectively. However, $30 \%$ of parents surveyed stated that they think it is acceptable for a child to develop tooth decay due to the difficulty in controlling how effectively they clean their teeth on a daily basis.

Difficulties regulating children's sugar consumption was also cited as a reason why many parents now accept tooth decay. Over a quarter (26\%) of parents surveyed admit this with a further $29 \%$ of parents surveyed believing that potentially painful oral health conditions, such as tooth decay, are pre-determined by a family history of oral health complaints and weak teeth.

More than 1 in 10 parents (14\%) claim that they think that decay in children's teeth is acceptable as all children will inevitably lose their milk teeth as they develop.

Denplan's research suggests that the Government's planned tax on sugar could be warmly welcomed by parents with almost half (45\%) of parents surveyed claiming that they believe that tooth decay can be prevented by limiting the amount of sugar in a child's diet. A further $40 \%$ of parents believe that tooth decay can be prevented by ensuring that children regularly see their dentist for a check-up. Despite this, when asked what actions they take to prevent their child developing decay just 1 in 5 (18\%) of parents said that they take their child to see the dentist once a year as soon as their first tooth appears.

Denplan's Big Summer Brush-Up campaign, along with the accompanying materials Denplan has produced, has been created to help practices support and guide families on their oral healthcare.

Denplan's Little Book of Healthy Smiles has also been produced, containing handy advice from dentists and tips on how to enthuse unwilling children to brush up on cleaning teeth, written for parents by parents.

Visit www.bigsummerbrushup.co.uk. 